\title{
A GESTÃO ESCOLAR PAUTADA NOS PRINCÍPIOS DE DIVERSIDADE E TECNOLOGIA
}

\section{ARTIGO DE REVISÃO}

PEREIRA, Walmir Fernandes ${ }^{1}$

PEREIRA, Walmir Fernandes. A gestão escolar pautada nos princípios de diversidade e tecnologia. Revista Científica Multidisciplinar Núcleo do Conhecimento. Ano 05, Ed. 08, Vol. 03, pp. 48-55. Agosto de 2020. ISSN: 2448-0959, Link de acesso: https://www.nucleodoconhecimento.com.br/educacao/diversidade-etecnologia

\section{RESUMO}

O presente trabalho traz reflexões acerca dos princípios de Diversidade e Tecnologia no papel da gestão escolar. É de fundamental importância a figura do gestor junto a sua equipe administrativa, docente e com toda a comunidade escolar (aluno, pais, professores e funcionários) desenvolvendo ações concretas que prezem pela presença das ferramentas e recursos tecnológicos nas práticas administrativas e pedagógicas, e o fortalecimento da cultura da diversidade dentro de encontros, palestras, discussões e atos do cotidiano de sua equipe. $\mathrm{O}$ objetivo deste artigo é

${ }^{1}$ Mestrado em andamento em Science in Emergent Technologies in Education. Especialização em andamento em Educação Inclusiva. Especialização em andamento em Psicopedagogia. Especialização em andamento em Docência e Diversidade. Especialização em Compreensão de Textos e Tradução da Língua Espanhola. Especialização em Ensino Religioso. Especialização em Metodologia da Língua Inglesa e Espanhola. Especialização em Gestão Escolar: Orientação e Supervisão. Aperfeiçoamento em andamento em Preparação e revisão: o trabalho com o texto - On-line. Aperfeiçoamento em Atendimento Escolar Especializado em Educação Especial e Inclusão. Graduação em Licenciatura em Pedagogia. Graduação em Licenciatura em Artes Visuais. Graduação em Letras. 
abordar os princípios de uso de Tecnologia e da diversidade inseridos na prática do Gestor escolar. A metodologia utilizada foi a pesquisa bibliográfica que fundamentou o trabalho trazendo abordagens de revisão feitas em artigos de periódicos científicos já publicados sobre as áreas de Tecnologia e Diversidade. Portanto o que vamos encontrar como resultados dessas discussões nesta pesquisa é que não se pode mais pensar em gestão escolar democrática e participativa que não preze por adotar em seu planejamento junto à comunidade escolar as questões relacionadas às Tecnologias no processo de ensino e a discussão de um ambiente diversificado que é a escola.

Palavras-chave: Gestão Escolar, tecnologias de informação e comunicação (TIC), diversidade social.

\section{INTRODUÇÃO}

A Gestão Escolar lida diariamente com os princípios de Diversidade e de uso da Tecnologia em suas realizações de trabalho. E este artigo visa fazer uma reflexão acerca dessas temáticas, onde esses princípios fazem-se necessários na prática administrativa e pedagógica do gestor.

No contexto educacional em que vivemos, a Era Digital e da Comunicação, fica difícil separamos as ações gestoras do uso de recursos e ferramentas tecnológicas, pois são muitos benefícios que poderão transformar a práxis gestora, trazendo modificações e novas propostas para o espaço escolar resultando uma a aprendizagem significativa dentro da unidade escolar.

E dentro deste mesmo cenário onde utilizamos a tecnologia, não podemos nos esquecer da temática da diversidade que permeia o espaço escolar, pois é notório afirmar que a escola é o local de maior pluralidade de etnias, ideologias, atitudes e diferenças que temos dentro de nossa sociedade.

Cabe então dizer que o gestor é quem vai articular esses princípios de tecnologia e diversidade dentro do lugar em que está inserido, utilizando metodologias 
diferenciadas das convencionais e ações pedagógicas junto a uma equipe diversificada para tratar dessas temáticas de forma que seja satisfatória e que crie um ambiente tecnológico e saudável de convivência entre equipe docente, administrativa, alunos e comunidade escolar.

Deste modo, temos o desafio do papel da Gestão Escolar que é trabalhar o comportamento organizacional de uma equipe multi diversificada em ações e pensamentos, mas que juntos têm a missão de promover um espaço que veja a inserção tecnológica como aliada e que saiba trabalhar com conceitos de diversidade através de oficinas, projetos e discussões com sua equipe docente e discente.

Este artigo trará em seu desenvolvimento o que os especialistas nas áreas de tecnologia e diversidade abordam para que seja trabalhado dentro do espaço acadêmico e administrativo em que a figura da gestão escolar exerce.

\section{FUNDAMENTAÇÃO TEÓRICA}

O gestor escolar precisa ter claro em suas ações pedagógicas e administrativos de que não há como se isentar do uso dos recursos e ferramentas tecnológicas nas atividades, projetos e oficinas desenvolvidas dentro da escola.

A internet e suas ferramentas são a realidade de nossos educandos e não tem como pensar processos de ensino aprendizagem isolados da TIC.

Para Brito e Purificação (2006, p. 20) "encontrasse em processo de transição na busca de uma civilização mais harmoniosa..." por isso, como os autores elencam é preciso priorizar os interesses de recursos novos, os digitais e eletrônicos, para desenvolver a aprendizagem de forma significativa.

E quanto ao princípio de diversidade dentro do espaço escolar, é importante ter um olhar consciente e reflexivo sobre a ótica das diferenças e das desigualdades sociais dentro de cada turma, dentro da equipe de funcionários e de toda a comunidade escolar ao redor daquela instituição. 
De acordo com Gomes (2008, p. 20) "diversidade faz parte do acontecer humano, ocorre na perspectiva biológica e cultural e estão inter-relacionados." Compreender a dimensão que se tem do diferente é o papel primordial da gestão, conscientização de comportamentos distintos.

Segundo Gomes (2008), o ser humano enquanto parte da diversidade biológica não pode ser entendido fora do contexto da diversidade cultural. Com essa citação fica explícito que a busca pela compreensão dos comportamentos dentro da escola, dentro das salas de aula parte de um direcionamento dos Planos Pedagógicos e das propostas e ações traçadas pela equipe gestora no PPP, Projeto Político e Pedagógico, daquela instituição.

É preciso pensar numa formação que atenda esses princípios e nenhum trabalho é planejado e executado de forma individual, usar tecnologias e trabalhar conceitos de respeito a diferenças trará exitosos resultados.

De acordo com Nunes (2003), uma direção de uma realidade que seja boa para todos capazes de produzir e constituir laços institucionais afetivos e sociais.

Pensar nesse tipo de formação é atender as necessidades de uma Educação que se preocupa com a formação autêntica e integral do indivíduo, e é de responsabilidade da gestão escolar junto com a sua equipe pensar em estratégias que visem trabalhos que trarão efetivas contribuições morais, humanas e tecnológicas.

Conforme Paulo Freire (1996, p. 15) " formar é muito mais do que puramente treinar o educando no desempenho de destrezas." Essa citação do nosso grande mestre da Educação brasileira, traz consigo a resposta de como precisamos trabalhar uma gestão que preze pela inserção tecnológica e valorização do ser diferente, pois somos uma sociedade plural.

Quando pensamos em como utilizar tecnologia em sala de aula, na sala da gestão da orientação e toda equipe, estamos pedindo com essa atitude, modificação de hábitos, queremos informatizar trabalhos, facilitando processos administrativos e 
pedagógicos, mudando o cenário educacional, colocando-o em contato com as mudanças sofridas por essa geração digital na qual já vivemos.

Para Moran (2000, p. 132) " não é suficiente adquirir televisão, videocassetes, computadores, sem que haja uma mudança básica da postura do educador." É crucial promover mudanças metodológicas no processo de ensino-aprendizagem.

E de acordo com Brito e Purificação (2006), o simples uso no espaço escolar não garante mudanças ou rupturas nas formas tradicionais de ensino e aprendizagem.

Quanto ao trabalho do gestor e dos docentes voltado à diversidade, podemos dizer que nas últimas décadas têm se pensado e discutido temas de superação dos processos de preconceito e discriminação dentro dos ambientes escolares.

Temos em nossa Constituição Federal de 1988 vários artigos que asseguram a pluralidade de ideias e de manifestações culturais , combatem estereótipos e ações discriminatórias.

Como salienta Cury (2005, p.30)

art. 206, o pluralismo de ideias e concepções pedagógicas. $\mathrm{O}$ art. 210, refere-se ao currículo, cujo qual pede respeito aos valores culturais e artísticos, nacionais e regionais. Do capítulo reservado à cultura o art. 215 afirma que o Estado garantirá a todos o pleno exercício dos direitos culturais e acesso às fontes da cultura nacional, e apoiará e incentivará a valorização e a difusão das manifestações culturais.

Temos como documentos a CF 1988 e a LBD 93094/96 como referenciais do reconhecimento das diferenças no contexto escolar. E cabe a gestão escolar junto a toda equipe repensar ações que versam essa temática nos espaços educacionais onde atuam. Que sejam realizados projetos, ações conjuntas de direção e professores que combatam a discriminação e o preconceito e assim promovam uma educação democrática e justa, contribuindo para formação de uma sociedade menos excludente. 
A educação como direito a sua efetivação em práticas sociais converte-se em instrumento de luta pela redução progressiva das desigualdades e extinção das discriminações e possibilita uma aproximação pacífica entre os povos do mundo, segundo Cury (2005).

E segundo Gadotti (2001, p. 11) "o ato de educar significa alimentar, criar, fazer sair, é a prática mais humana, considerando-se a profundidade e a amplitude de sua influência na existência dos homens."

Para acontecer uma gestão eficiente é preciso investimento na formação continuada das equipes de trabalho, principalmente na equipe docente, buscando atualização no uso de ferramentas e recursos tecnológicos, promoção de debates e discussões acerca da diversidade no ambiente escolar.

Almeida (2005) evidencia-se que a importância de se desenvolver programas de formação voltados para as especificidades do trabalho dos gestores, alicerçados na articulação entre as dimensões administrativas e pedagógicas, na integração entre tecnologias e metodologias de formação, tendo as tecnologias como artefatos que favorecem os encontros entre pessoas, valores, concepções, práticas e emoções.

Assim, o papel do gestor escolar requerer comprometimento, capacidade e habilidades administrativas, liderança, ações que são permeadas pela autonomia, liberdade, atitudes democráticas e responsabilidade.

A postura adotada pelo gestor e sua equipe ao tratar de temas de diversidade nasce de propostas conjuntas com a comunidade escolar, onde juntos vão traçar ações para uma gestão que efetive o respeito e a valorização das diferenças físicas, sociais presentes em nossa sociedade contemporânea.

É de fundamental importância discutir a diversidade em reuniões pedagógicas com os docentes, com a equipe administrativa e com os pais e alunos, buscando com essas discussões desconstruir e reconstruir significados e conceitos impregnados. 
Sabemos que vivemos que uma sociedade marcada pela diversidade sociocultural, então é necessário analisar a temática de desigualdade social e preconceitos dentro de reuniões pedagógicas, discussões e debates dentro de sala de aula, se possível com a presença do gestor e da equipe docente. Todos devem se sentir responsáveis pela promoção de um espaço educativo que visa à valorização da diferença, seja ela qual for buscando como educadores analisar a situação sócio-ético-cultural da sociedade.

$\mathrm{Na}$ situação de classe agregam-se outras condições tais como: pertencimento étnico, diferenças etárias, de gênero, geográficas, religiosas, de visões de mundo, projetos individuais, desejos, valores, experiências vividas e ressignificadas (CAPELO, 2003).

A partir dessas discussões, avançar com o trabalho de uma gestão participativa e democrática redefinindo junto à comunidade escolar o conceito de "diferente", de" diverso" seria um passo crucial, porque ajudaria a não criar o sentimento de exclusão dentro da unidade escolar.

Para Martins (2002, p. 26) a exclusão seria

conjunto das dificuldades, dos modos e dos problemas de uma inclusão precária e instável, marginal. A inclusão daqueles que estão sendo alcançados pela nova desigualdade social produzida pelas grandes transformações econômicas e para os quais há senão, na sociedade , lugares residuais.

Como mencionado pelo autor, vivemos em uma sociedade capitalista excludente, fator que nós como educadores vivenciamos diariamente, seja através da falta do acesso aos recursos e ferramentas tecnológicas e da desigualdade social de nossa equipe e de nossos alunos.

O papel do Gestor Escolar é de executar em suas práticas administrativas, e no caso das escolas, nas ações pedagógicas também, práticas que tratam do conceito de diversidade dentro de todos os setores: secretarias onde atendem professores, pais e alunos, portarias das unidades escolares, salas de aula, reuniões administrativas, pedagógicas, de pais e junto aos Conselhos Escolares e Grêmio Estudantil. 
As diferenças, por sua vez, são construídas pelos sujeitos sociais ao longo do processo histórico e cultural, no processo de adaptação do homem e da mulher ao meio social e no contexto das relações de poder (BARROS, 2008).

Portanto, podemos dizer que se o gestor consegue planejar com toda a equipe que a prática acadêmica e administrativa seja trabalhos que executem de forma significativa os princípios de tecnologia e diversidade, teremos uma escola aliada ao mundo contemporâneo, e não uma escola aquém do que o mercado de trabalho, as universidades e as empresas esperam receber. Vasquez (2009) salienta que um profissional que deseja que seu fazer pedagógico se aproxime das necessidades educacionais de seus alunos- caminhar no sentido da compreensão de sua sala de aula, lançar um olhar com foco sobre suas práticas pedagógicas e sobre a aprendizagem - faz uma diferença.

\section{CONCLUSÃO}

Este trabalho teve por objetivo apresentar através de uma revisão bibliográfica de artigos de autores especialistas nos assuntos de Diversidade e Tecnologia na Gestão Escolar, o papel do gestor escolar junto a uma equipe heterogênea como deve ser o trabalho que visa o uso de tecnologia com a adoção de os novos procedimentos metodológicos nas salas de aula que não excluem esses recursos e que promova um espaço diversificado.

Pensar a gestão de escola sem valorizar um planejamento de ações que lidam com o comportamento organizacional não é mais possível para um cargo de gestão, pois lidamos com diferentes pessoais, principalmente nas escolas, são faixas etárias diferentes, culturais totalmente distintas.

Portanto, o papel do gestor é de formar essa equipe que preze por estes princípios, que planeje e execute ações que preparem nossos alunos para esta geração tecnológica e cada vez mais diferente dos conceitos de séculos passados, que a busca pela formação seja constante e que haja dentro dos espaços laborais uma relação interpessoal que traga êxito para todos. 


\section{REFERÊNCIAS}

ALMEIDA, M. E. B de. Gestão de tecnologias na escola: possibilidades de uma prática democrática. In: Salto para o Futuro. Série Integração de tecnologias, linguagens e representações. Rio de Janeiro: TV Escola, SEED-MEC, 2005.

AMARAL, Lígia Assumpção. Diferenças, Estigma e Preconceito: o desafio da inclusão. In: OLIVEIRA, Marta Kohl de; REGO, Teresa Cristina; SOUZA, Denise Trento R. (orgs.). Psicologia, Educação e as temáticas da vida contemporânea. São Paulo: Moderna, 2002. p. 233- 248.

BARROS, M. (org.). Diversidade Cultural: da promoção à proteção. Belo Horizonte: Autêntica, 2008.

BRITO, G. S.; PURIFICAÇÃO, I. C. Educação e novas tecnologias: um repensar. Curitiba: Ibpex, 2006.

CAPELO, M. R. C. Diversidade Sociocultural na escola e a dialética da exclusão/inclusão. In GUSMÃO, Neusa. Diversidade, cultura e educação: olhares cruzados. São Paulo. Biruta, 2003.

CURY, C. R. J. Direito à Educação: Direito à Igualdade, Direito à Diferença. Cadernos de Pesquisa, São Paulo, n. 116, p. 245-262, jul. 2005.

FREIRE, Paulo. Pedagogia da Autonomia.1996.

GADOTTI, Moacir. Concepção Dialética da Educação: Um Estudo Introdutório. São Paulo: Cortez, 2001.

GOMES, N. L. Desigualdades e diversidade na educação. Educ. Soc. [online]. 2012, vol.33, n.120 [cited 2016-09-19], pp.687-693. Disponível em: http://www.scielo.br/scielo.php?script=sci_arttext\&pid=S0101-73302012000300002. Acesso em 19 de setembro de 2016. 
GOMES, N. L. Indagações sobre currículo: diversidade e currículo / [Nilma Lino Gomes]; organização do documento Jeanete Beauchamp, Sandra Denise Pagel, Aricélia Ribeiro do Nascimento. - Brasília: Ministério da Educação, Secretaria de Educação Básica, 2008.

MARTINS, J. S. A Sociedade vista do Abismo: novos estudos sobre exclusão, pobreza e classes sociais. Petrópolis, RJ: Vozes, 2002.

MORAN, José M. Gestão inovadora da escola com tecnologias in: VIEIRA, Alexandre Thomaz (org.). Gestão educacional e tecnologia. São Paulo, Avercamp, 2003. p. 151164.

NÓVOA, Antonio. Formação contínua professores: realidades e perspectivas. Aveiro/Portugal: universidade de Aveiro, 1991.

NUNES, César. Educar para a Emancipação. Florianópolis: Sophos, 2003. 128p. Educar para a Emancipação. In: Ciclo de Palestras, 2003, Marília, p.2. 07 mar. 2003.

OSÓRIO, A. C. do N. Inclusão Escolar: em busca de fundamentos na prática social. In: Ensaios Pedagógicos: construindo escolas inclusivas, 1ed. Brasília, 2005, p. 21 36.

VASQUEZ, Beatriz Sanz. Das memórias humanas à memória virtual coletiva: uma construção a partir da história de vida utilizando AVA. Dissertação de mestrado. Universidade Estadual de Campinas, SP, 2009.

Enviado: Maio, 2020.

Aprovado: Agosto, 2020. 